\title{
Fortbildungskosten sind auch ohne beruflichen Bezug steuerlich absetzbar
}

- Nach einem Urteil des Bundesfinanzhofs (BFH) können niedergelassene Ärzte, die an einer Fortbildung teilnehmen, die nicht komplett beruflich motiviert ist, die Kosten zumindest anteilig als Betriebsausgaben geltend machen ( $\mathrm{Az}$. VI R 66/04).

Im konkreten Fall hatte ein angestellter Unfallarzt an einem sportmedizinischen Wochenkurs im Ausland teilgenommen. Die Fortbildung war Teil der von der Ärztekammer geforderten Voraussetzun- gen für den Erwerb der Zusatzbezeichnung „Sportmedizin“. Die Ausgaben machte der angestellte Arzt komplett als Werbungskosten bei den Einkünften aus nicht selbstständiger Arbeit geltend, das zuständige Finanzamt lehnte dies ab. Der Bundesfinanzhof bestätigte jedoch eine bereits in der Vorinstanz gefällte Entscheidung, weil die Aufwendungen anhand der Zeitanteile zur Hälfte als beruflich veranlasst gewertet werden können.

\section{MMW Kommentar}

Das Urteil ist von doppelter Bedeutung, da zugleich auch die Rechtsprechung mit Berufung auf den Beschluss des Großen Senats des BFH (GrS 1/06) revidiert wurde. Künftig sind deshalb Aufwendungen, die beruflich und privat veranlasst sind, immer in abziehbare Betriebsausgaben/ Werbungskosten und nicht abziehbare Aufwendungen für die private Lebensführung aufzuteilen.

\section{Rahmenbedingungen für Patientenquittungen}

- Der Anspruch des Patienten auf die Ausstellung einer Patientenquittung besteht gem. §305 Abs. 1 SGB V. Dieser Anspruch besteht gegenüber Vertragsärzten, medizinischen Versorgungszentren und Krankenhäusern.

Diese Patientenquittung ist an keine bestimmte Form gebunden, d.h. es gibt keinen entsprechenden verbindlichen Vordruck. Aus der Quittung müssen lediglich neben den abgerechneten Gebührenziffern die Leistungen in verständlicher Form und die voraussichtlichen Kosten hervorgehen. Auch besteht keine Verpflichtung, eine Patientenquittung mithilfe des Praxisverwaltungssystems zu erstellen. Diese können sogar manuell erstellt werden.

Gemäß $\S 305$ Abs. 2 S. 3 SGB V hat der Patient für eine solche quartalsweise schriftliche Unterrichtung eine Aufwandspauschale in Höhe von 1 Euro zuzüglich Versandkosten zu erstatten. Die Weitergabe dieser Informationen soll zu mehr Transparenz führen.

\section{MMW Kommentar}

Seit Inkrafttreten dieser Regelung hat zwar nur ein geringer Anteil der Patienten die Gelegenheit genutzt, sich eine Patientenquittung erstellen zu lassen. Im Zusammenhang mit Bescheinigungen für sog. Bonushefte scheint sich das allerdings zu ändern. Als Alternative zur Ausstellung der Patientenquittung könnte deshalb die Möglichkeit nach § 305 Abs. 1 SGB V genutzt werden, eine solche Patientenquit- tung bei der Krankenkasse zu beantragen. Von einigen Betriebskrankenkassen wird mittlerweile sogar die Möglichkeit angeboten, eine Patientenquittung direkt über das Internet erstellen zu lassen (www. versichertenauskunft.de). Ob diese einfache und kostengünstige Lösung in Zukunft auch von weiteren Kostenträgern angeboten wird, liegt jedoch leider im Ermessen jeder einzelnen Krankenkasse.

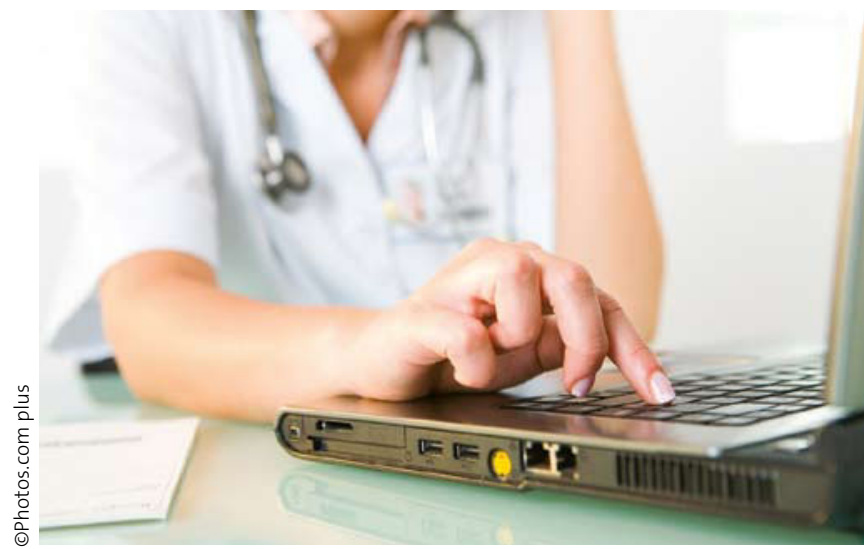

4 Wie Sie eine Patientenquittung ausstellen, bleibt Ihnen überlassen. 